\title{
S TРАНСФОРМАШИЯ ПРАВОВЫХ U

Калабекова С.В., Напсо М.Д.

\section{СОХРАНЕНИЕ ЭТНОКУЛЬТУРНОЙ САМОБЫТНОСТИ КАК ФАКТОР РЕАЛИЗАЦИИ НАЦИОНАЛЬНЫХ ИНТЕРЕСОВ В УСЛОВИЯХ ОБЩЕСТВА ПОСТМОДЕРНА}

\begin{abstract}
Аннотация: В современных условиях особое звучание приобретает проблема сохранения этнокультурной специфики как одного из важнейших механизмов реализации принцииов национальной жизни. Это особо актуально для эпохи глобализации, которая, с одной стороны, усиливает универсалистские тенденции, с другой, требует всемерного развития и сохранения национального колорита как необходимого условия успешности глобализационного проекта. В этой связи особо востребованной становится реализация права на самобытность - не только индивидуального (как права человека), но и коллективного (в качестве права народа).
\end{abstract}

Ключевые слова: Юриспруденция, этнонациональные интересы, национальные устремления, глобализация, постмодернизм, культурный релятивизм, унификация культур, универсализм, право на самобытность, право на самоопределение

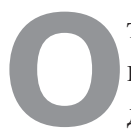

тличительной чертой цивилизационного развития периода глобализации является единство двух процессов: с одной стороны, расширение и углубление взаимодействий различных этносоциальных общностей между собой, результатом чего становится формирование и развитие общих, сходных черт, с другой стороны, все большее осознание народами, странами, регионами, цивилизациями самих себя, собственной непохожести и уникальности, которую приходится сохранять и развивать в задаваемых глобализацией рамках. Глобализация - это не только мир без границ, но и мир разнообразия различий. Стремление народов сохранить себя как этническую группу, обладающую специфической культурой, и воспроизводить себя как отдельную социальную общность ширится, несмотря на постоянно углубляющиеся процессы интернационализации. Как ни парадоксально, рост этнического самосознания также есть результат расширения и углубления взаимодействий различных этносоциальных общностей между собой, формирования и развития общих, сходных черт.

В условиях глобализации и в эпоху постмодернизма со свойственным им активным замещением традиционных культурных ценностей на искусственные конструкты, символы и симулякры коллективные этнические права можно рассматривать как институциональный механизм защиты самих этнических общностей. Множественные глобализационные угрозы (нивелирование и унификация культур, интересов, потребностей, масштабные миграции и активные процессы смешения населения, довление информационных технологий и т.п.) в первую очередь затрудняют процесс сохранения и воспроизведения этносов как отдельных социальных групп, являющихся носителями своеобразных культур. Эти угрозы представляют реальную и наибольшую опасность именно для этнонациональной самобытности, которая имеет исключительную важность для этнического развития и самочувствия, для существования этнической общности как таковой. Поэтому право на самобытность многими рассматривается в контексте этнокультурной безопасности. Если прибегнуть к распространенному пониманию безопасности как «состоянию устойчивого функционирования и воспроизводства социального объекта/субъекта, поддерживаемое с помощью особой институциональной среды» ${ }^{1}$, то этнонациональная безопасность, с одной стороны, предполагает сохранение этноса (субъекта) посредством защиты этнокультурной самобытности как его институциональной среды от разрушительных воздействий (в том числе и со стороны иных этносов), с другой, сама требует создания институциональной среды в виде законодательства, призванного оптимизировать и упорядочить процессы воздействия различных систем ценностей на этнонациональные культуры. Таким образом, безопасность

${ }^{1}$ Миграция и безопасность в России. - М., 2000. - С. 153. 


\section{Право и политика $6(162) \cdot 2013$}

этноса обеспечивается особой институциональной средой - этнонациональной самобытностью, которая в свою очередь защищается посредством иной институциональной среды - законодательства. Следовательно, этнокультурная безопасность напрямую зависит от качества правового регулирования.

Основу национальных интересов составляет стремление этнических групп сохранить себя, особость своей культуры. Однако для реализации национальных интересов решающее значение имеет понимание должного положения народа не столько самим народом (что находит отражение в национальных интересах), сколько обществом, государством (на этом основывается государственная национальная политика). Важность последнего очевидна: именно это обеспечивает целенаправленную деятельность по созданию необходимых условий существования и развития народов, разработку социально-правовых механизмов реализации избранной политики, среди которых особую роль играют права народов. Появление прав народов как механизма обеспечения должного положения народов стало своего рода официальным признанием существования национальных интересов. Кроме того, содержание основных из них: права на существование, права на самоопределение и самоуправление, права на самобытность - позволяет понять, реализация каких национальных интересов представляет наибольшую актуальность как для самих этнических общностей, так и для государства и мирового сообщества в целом.

Утверждение коллективного права на самобытность есть признания значимости национальных чувств как стремления этнической общности к самосохранению и самоутверждению, которое никак не может быть обеспечено посредством реализации индивидуального права человека на самобытность. Более того, право индивида на самобытность не может быть полностью реализовано без обеспечения права на самобытность для самой этнической общности. Ведь самобытность есть качество, сущностно определяющее этническую группу, поэтому защита самобытности предполагает прежде всего защиту этнической группы как таковой. Право человека на самобытность подразумевает свободу выбора в вопросах идентификации себя с определенной общностью, культурой - оно не располагает механизмами, позволяющими обеспечить сохранность и всемерное развитие самой культуры как важнейшего этнонационального феномена. Ими располагает именно коллективное право - право народа на самобытность.

Нельзя не согласиться с выводом В.В.Кочаряна о том, что «только группа может обладать правом на самобытность, ибо только ей как таковой может быть присущ комплекс этнических, культурных, религиозных, языковых признаков, составляющих содержание ее идентичности, отличающей ее от других групп... Такой компонент самобытности, как культура, созидается и является продуктом коллективной активности, язык как средство общения тоже функционирует только в группе...»². И с мнением С.С. Юрьева: «Проблема противопоставления индивидуальных и групповых прав во многом искусственна, ибо по своей социальной природе культурные или языковые права не могут не быть коллективными... Многие обязанности государств направлены на поддержку культуры, религии, языка, т.е. таких форм проявления самобытности, которые реализуются исключительно в относительно устойчивой социальной группе. В связи с этим представляется, что отсутствие в международных актах характеристики тех или иных прав как принадлежащих именно этнической общности, а не индивиду, обусловлено, скорее, политическими..., чем правовыми соображениями» ${ }^{3}$. Права и Ф.А. Ахметшина, говоря, что «отдельный человек не может быть «самобытным» в том смысле, какой мы придаем обычно этому понятию. Самобытна может быть культура, образ жизни какоголибо социального коллектива, например, меньшинства. Нельзя нанести ущерб самобытности этнической группы в целом, нарушив право одного из членов этой группы на использование родного языка. И напротив, повсеместное запрещение использования языка в местности, населенной меньшинством, может повредить этой самобытности. Таким образом, самобытность - это ценность, принадлежащая социальной общности, а не индивидам, и право на уважение этой ценности является правом меньшинства, т. е. коллективным правом» ${ }^{4}$. Утрата таких этнических признаков, как язык, территория, традиционная культура, историческая память крайне губительно действует на этническое самосознание, которое является важнейшим элементом правосубъектности этнических групп: отсутствие развитого этнического самосознания значительно уменьшает возможности этнической группы выступать субъектом правоотношений, формировать осознанные интересы, выдвигать и защищать их. Однако в основе регламентации права на самобытность должна лежать не столько защита культуры, языка, традиций, верований, сколько защита прав самих носителей - групп и индивидов, что в одинаковой мере относится и к вопросу соблюдения прав человека, народов, отдельных этнических групп (национальных меньшинств, коренных народов).

В вопросе об особой значимости права на самобытность мы разделяем ту точку зрения, что продвижение ко

\footnotetext{
2 Цит. по: Ахметшина Ф.А. Право на самобытность и решение вопроса средствами высшей школы //http:// globkazan.narod. $\mathrm{ru} / / 2003 / \mathrm{a} 19 . \mathrm{htm}$.

${ }^{3}$ Юрьев С.С. Правовой статус национальных меньшинств (теоретико-правовые аспекты). - М., 2000. - С. 243.

${ }^{4}$ Ахметиина Ф.А. Право на самобытность и решение вопроса средствами высшей школы //http:// globkazan.narod.ru//2003/a19.htm.
} 
всё более единому миру идет в том числе и через более полную реализацию права на самобытность, наряду с обретением институтом права человека всё большего значения, расширением прав и повышением статуса меньшинств, общей демократизацией общества, расширением возможностей самоуправления (при наличии правовой и реальной возможности на самоопределение вплоть до сецессии) ${ }^{5}$.

Именно как можно более полное осуществление права на самобытность и на самоуправление является наилучшим способом «минимизирования издержек», связанных с реализацией права на самоопределение. На наш взгляд, децентрализация, право на самоуправление и предоставление широких возможностей по защите своей этнонациональной самобытности есть неотъемлемая часть права на самоопределение, один из правовых способов его реализации. Именно на этом основывается Декларация «О хартии народов и регионов» (Нюрнберг, 2003), исходящая из того, что «человечество не состоит только из государств и их основных наций. Оно представляет собой исторически сложившееся тесное переплетение народов и народностей, этнических и прочих групп, находящихся в численном большинстве или меньшинстве, а также наций, которые не имеют своей государственности, но имеют равное с основными нациями право на защиту своей национальной идентичности и развитие своей национальной общности». Актуальность в современных условиях наиболее полного обеспечения самобытности и самостоятельности народов и регионов Хартия объясняет тем, что формирование в сфере международных отношений коллективной воли и коллективных действий всё больше происходит в условиях централизации процессов принятия политических решений и удаления их от граждан, что требует «создания широкой, насколько это возможно, автономии малых национально-культурных сообществ». Именно последнее обеспечит сохранение национального многообразия малых национально-культурных сообществ и привлечет их к участию в процессах принятия политических решений. Это вкупе с последовательным соблюдением принципа субсидиарности, когда политические решения формируются на местах, в непосредственной близости к гражданам, должно позволить преодолеть национальные конфликты, внутриевропейское размежевание и продвинуться по пути установления нового европейского миропорядка, который есть «Европейский Союз, с одной стороны, и максимально возможная автономия для малых национально-культурных сообществ, с другой стороны» - «Европа может стать примером для

\footnotetext{
${ }^{5}$ Нистен-Хаарала С., Фурман Д. Право на отделение // http://www.sakhara-center.ru/publications/sec/009/html; Стешенко Л.А. Многонациональная Россия: государственноправовое развитие. X-XXI вв. - М., 2002. - С. 194.
}

всего мира, если она отойдет от модели более или менее централисткого национального государства и обратится к модели многообразия и единства путем гарантии группам прав и свобод, автономии и права на самоопределение».

Главным инструментом достижения этой цели является «расширение рамок прав человека как индивидуума за счет включения в них дополнительного права этнических групп». Первым шагом на пути к стабильности и демократии (предупреждению конфликтов и очагов напряженности) в Европе является «гарантия группам минимума прав и свобод», следующий этап - «когда этнические и национальные сообщества, нации, находящиеся в численном большинстве, и национальные меньшинства получат максимально полную автономию, и более того, федеративные структуры и структуры самоопределения»: «прежде за этническими группами должны быть признаны права, защищающие их равенство и национальное своеобразие, а вопросы автономии, федерализма и самоопределения должны быть поставлены в повестку дня Европы». Таким образом, Хартия признает особую важность для бесконфликтной реализации права на самоопределение права на национальное своеобразие, на защиту национальной идентичности, и права на автономию, что, в свою очередь, основывается на предоставлении всем этническим группам (меньшинствам и находящимся в большинстве) на «территории их поселения» минимума прав. Каких же? Примечательно, что наравне с такими правами, традиционно объемлемыми правом на самобытность: осуществление национально-культурной автономии и автономии в области образования; дву-и многоязычность в официальной сфере и общественных учреждениях; создание собственных учебных и воспитательных заведений, обучение в школах на родном языке; создание собственных учреждений культуры и их финансирование; доступ к средствам коммуникации и информации; гарантия экономических и экологических условий жизни; использование хозяйственных и природных ресурсов своих территорий; возможность возвращения для изгнанных народов и народностей; беспрепятственное установление и поддержание контактов с носителями своей исконной культуры за рубежом и другими национально-этническими группами - изложены и права политические: активное участие всех этнических групп в общественно-политической жизни через гарантированное представительство в политических институтах, обеспечиваемое соответствующим устройством (гарантирующим подлинное равноправие различных этнических групп), доступ к службе в государственных учреждениях и участие в процессах принятия политических решений. Это позволяет думать, что Европа намерена сделать из этнических групп реальных акторов политической жизни, что, несомненно, значительно снижает риски процессов самоопределения - автономизации и суверенизации. 


\section{Право и политика 6 (162) 2013}

Хартия сохраняет традиционный подход к праву на автономию. Так, согласно ст.4 Хартии, для этнических групп, составляющих большинство в местах их поселения и регионах, она предоставляется в виде территориальной автономии в «желаемых объеме и форме», с делегированием на места законодательных и исполнительных функций, определяемых в соответствии с принципом субсидиарности, а для некомпактно проживающих этнических меньшинств - «личную автономию», понимаемую, главным образом, как языковую и национально-культурную, включающую и необходимую для ее реализации и финансовую автономию, но также в «желаемых объеме и форме». Автономия в ее «территориальной» форме позволяет получить полноправное представительство в нижних палатах парламентов, которые совместно с представителями верхних палат национальных парламентов «должны участвовать в формировании коллективной воли европейских стран». Следующим шагом в установлении самостоятельности является «конституционная автономия (федерализм)», позволяющая «этносам и регионам достичь высокой степени национальной идентичности, более полного осуществления своих прав на самоопределение и участие в решении государственных вопросов...». Таким образом, как мы уже неоднократно говорили, автономизация имеет целью не только «сбережение» национального своеобразия, но - и это главное - превращение этнических сообществ в реальную политическую силу, имеющую свои интересы, волю и цели и возможность их выразить и отстоять. А это крайне важно для процесса этнического самоутверждения.

Поэтому на право на самоопределение Хартия смотрит и с этой точки зрения: «Вне зависимости от того, как международное право решает вопрос о глубине реализации народами права на самоопределение, самоопределение должно стать доминирующим организующим принципом с ичелью избежания навязывания чужой воли мальм и большим народам, национальным группам и регионам». Следовательно, право на самоопределение Хартией понимается как правовой механизм определения, установления и защиты собственной воли и законного противодействия диктату воли чужой, который имеет целью не постоянное дробление государств, а сохранение их целостности посредством создания федералистских структур. В таком контексте «процесс самоопределения служит интересам подлинного федерализма, а административное деление и границы, проведенные без учета права народов на самоопределение внутри...федерации, означают навязывание чужой воли» ${ }^{6}$.

\footnotetext{
${ }^{6}$ Декларация «О хартии народов и регионов» (Брновская программа) (Нюрнберг, 2003)// http:// www.balkaria.info/events/zakon/ declaration.htm.
}

Защита этнонациональных интересов, выраженных соответствующей волей, от гнета зависимости - прямая задача права на самоопределение, но его главная роль - обеспечение успешного этнонационального развития в условиях веками складывавшегося геокультурного, экономического, политического пространства. «Самоопределение и государственная независимость - явления разнопорядковые. Не всегда, как свидетельствует исторический политический опыт, достижение независимости обеспечивает развитие наций, т.е. реального самоопределения...Право наций и народов на самоопределение...в конечном счете... право народа на дальнейшее развитие. Определяющим признаком, позволяющим определить это право, является наличие или отсутствие юридических гарантий, конституционных предпосылок для развития наций (или народов)»7. В условиях глобализации особую важность имеет именно развитие наций и народов в условиях уже сложившегося контекста, совместной деятельности по обустройству территорий, сотворчества культур, сосуществования вероисповеданий, образов жизни, а не вне его. Это проблема не только утверждения принципов равноправия, партнерства и паритета интересов, но и преодоления былых обид, недоверия, недопонимания, межнациональной конфликтности, что возможно на пути все более полной реализации индивидуальных и коллективных прав.

И в этом смысле интерес представляет Хартия «О гражданских правах народов Российской Федерации», принятая на II съезде Ассамблеи народов России в 2000 г. и предлагающая «доктрину самобытного и равноправного развития и сотрудничества народов и граждан всех национальностей России, их взаимной ответственности за судьбу каждого народа, культуры и языка, ответственности за демократические перспективы единой общности многонационального народа Российской Федерации». Главное, что сразу же обращает на себя внимание, - отсутствие права на самоопределение, что компенсируется установлением широчайшего круга прав и свобод народов: право на достойное существование; право на уважение национальной, культурной, исторической и языковой самобытности; право на защиту культурных и социальноисторических основ жизнедеятельности; право на широкую автономию и самоуправление; право объединяться в национально-культурные автономии и межнациональные общности; право формировать ассоциации для сохранения этнокультурной самобытности, для межнационального и межкультурного сотворчества; право на экономическую и экологическую безопасность, охрану окружающей природной и этнокультурной среды обитания, проживания и традиционной хозяйственной деятельности; право

\footnotetext{
${ }^{7}$ Стешенко Л.А. Правовая политика России в сфере национальных отношений: теоретическое и историко-сравнительное исследование: Автореф. дис...докт.юрид.наук. - М., 2003. - С. 15,14.
} 
поддерживать и развивать свои экономические и социальные системы жизнеобеспечения и виды хозяйственной деятельности; право осуществлять традиционное природопользование; право влиять на определение приоритетов своего развития; право на этнокультурную самобытность, сохранение и развитие родных языков, отправление национальных и религиозных традиций и обычаев; право на историческую память, сохранение созидательных национальных ценностей; право практиковать и развивать духовные и религиозные ценности, обычаи и церемонии, поддерживать и защищать свои религиозные, культовые и культурные центры и др. ${ }^{8}$.

Особая важность права на самобытность заключается в том, что оно представляет собой юридическую формулу признания фактических различий и право на них, своего рода право на неравенство в значении права быть иным. В Декларации о расе и расовых предрассудках (1978), с одной стороны, указано, что люди рождаются равными в достоинстве и в правах, следовательно, равенство людей следует понимать как признание равноценности каждого и всех и признание за каждым и всеми равноправия на права. С другой, замечается, что люди различны и различия между ними носят объективный характер и объясняются географическими, историческими, политическими, экономическими, социальными и культурными факторами. И поэтому «все люди и группы людей имеют право отличаться друг от друга, рассматривать себя как таковых и считаться таковыми»9. Именно эти различия придают людям, их сообществам неповторимые специфические черты, естественным образом выделяя и обособляя их. В современных условиях стремление сохранить свою этнокультурную специфику, свою непохожесть и в этом смысле быть неравным другим столь же ярко выражено, как и сопротивление разным формам дискриминации, имеющей место в силу наличия тех или иных различий.

Как видим, неравенство может иметь характер естественного права. Доводы в пользу этого мнения находим у С.С. Юрьева: «Как объективное социальное явление самобытность, по сути, является антиподом фактического и политического равенства. Следствием стремления распространить принцип равенства на те сферы, где... этого равенства нет и быть не может, является неразрешимое противоречие, выражающееся, применительно к этнонациональным вопросам, либо в попытках создания моноэтнических государств через насильственную ассимиляцию, «этнические чистки», массовые депортации - т.е. в нарушениях прав меньшинства, либо в создании особых, «защитных», норм для них, т.е. исходя

\footnotetext{
${ }^{8}$ Хартия Ассамблеи народов России «О гражданских правах народов Российской Федерации»// http:// anrorg.ru/Hartia.htm.

${ }^{9}$ Декларация о расе и расовых предрассудках (1978) - Доступно $<$ http://www.un.org/russia/document/declarat/racism.htm>
}

из «рафинированной» идеи равенства, - в нарушениях прав большинства. Современное общество ушло от... учета не только формальных, но и реальных качеств людей, остановившись на «равенстве перед законом»... фактические различия людей не нашли адекватного выражения в фундаментальных правовых идеях, хотя при разрешении многих насущных вопросов... именно «различия» являются предметом правового регулирования. Дополнение идеи равенства идеей самобытности позволило бы «снять» имеющиеся противоречия. Поэтому признание на международном уровне самобытности не только как некоей социальной данности, но и в качестве правового принципа, влекущего особое правовое регулирование соответствующих общественных отношений, ослабило бы излишний универсализм «равенства»в пользу справедливости и общего блага» ${ }^{10}$. Наличие лишь формально-юридического равенства может иметь последствием «дискриминацию в результате отсутствия дифференциации» ${ }^{11}$. Именно такая форма дискриминации в наши дни встречает все большее сопротивление.

Изучение конституционно-правовых норм позволяет прийти к выводу о том, что право на непохожесть, право на различия, право на самобытность в современном праве обеспечивается посредством, главным образом, трёх прав - права индивида на национальную принадлежность, права индивида развивать собственную культуру и пользоваться родным языком и права меньшинств (индивидуальное и коллективное) на самобытность. Особенно ярко эта сложившаяся правовая традиция нашла свое отражение в конституциях государств, образованных на территории бывшего социалистического лагеря. Так, в ст.ст. 44,45 Конституции Азербайджана (1997) указано, что «каждый обладает правом сохранять свою национальную принадлежность. Никто не может быть принужден изменить свою национальную принадлежность... Каждый обладает правом пользоваться родным языком. Каждый обладает правом получить воспитание, образование и заниматься творчеством на любом языке по своему желанию. Никто не может быть лишен права пользования родным языком». Конституция Албании (1998), ст. 20, предоставляет права представителям национальных меньшинств «право свободно, без запрета и принуждения, выражать свою этническую, культурную, религиозную и языковую самобытность», «право сохранять ее и развивать, обучать и учиться на родном языке, равно как и объединяться в

\footnotetext{
${ }^{10}$ Юрьев С.С. Национальные меньшинства в правовом измерении: Научные исследования XX века и правовые варианты решения проблемы национальных меньшинств. - М., 2000. - С. 245.

${ }^{11}$ Кряжсков В.А. Права коренных малочисленных народов России: методология регулирования // Государство и право. - 1997. № $1 .-$ C. 20 .
} 


\section{Право и политика $6(162) \cdot 2013$}

организации и общества по защите своих интересов и своей самобытности». В Конституции Болгарии (1991), ст. 54, законодатель предпочел говорить о праве индивида развивать свою культуру в соответствии со своей этнической принадлежностью вкупе с правом пользоваться национальными и общечеловеческими культурными ценностями (авторы Конституции Грузии пошли по этому же пути). Конституция Македонии (1991) говорит о свободном определении национальной принадлежности как об одной из основополагающих ценностей конституционного устройства (ст.8) и наделяет «представителей национальностей» правом «свободно выражать, беречь и развивать свою национальную идентичность и национальные особенности», гарантируя «защиту этнической, культурной, языковой и религиозной идентичности национальностей» (ст.48). В Конституции Армении (2005), ст.41, как и в Конституции Молдовы (1994), ст.10, и Конституции Хорватии (1990), ст.15, право на самобытность изложено несколько иначе - как право каждого, но все же право индивидуальное: «Каждый имеет право на сохранение своей национальной и этнической самобытности. Лица, принадлежащие к национальным меньшинствам, имеют право на сохранение и развитие своих традиций, религии, языка и культуры». При этом Конституции Хорватии представителям всех народов и национальных меньшинств гарантируется не только свободу «выражения народной принадлежности, свободное использование своего языка и письменности», но и право на культурную автономию. А Конституция Молдовы, признавая и гарантируя «право всех граждан на сохранение, развитие и выражение этнической, культурной, языковой и религиозной самобытности», подчеркивает, что основу государства «составляет единство народа Республики Молдова» и сама статья носит весьма характерное название «Единство народа и право на самобытность». Этот момент нашел отражение в Конституции Грузии и Конституции Украины, в частности, в последней, в ст.11, говорится, что «государство содействует консолидации и развитию украинской нации, ее исторического сознания, традиций и культуры, а также развитию этнической, культурной, языковой и религиозной самобытности всех коренных народов и национальных меньшинств Украины».

Что же касается, например, конституций европейских и иных развитых стран, то в большинстве своем они не содержат вышеназванных положений (или содержат положения о правах меньшинств и коренных народов), исключение составляют государства с федеративным государственным устройством, но их конституции оперируют не столько понятием «развитие национальной самобытности», сколько «поддержание культурного многообразия», «приумножение многокультурного наследия». Более того, современные европейские конституции, в частности Конституция Португалии (1997), говорят о стремлении развивать европейскую самобытность ${ }^{12}$.

Таким образом, право на самобытность традиционно понимается как право меньшинств и коренных народов и лиц, к ним принадлежащих, на сохранение своей культуры. Кроме того, можно говорить о развитии тенденции его расширительного толкования как права любого индивида на выражение своей национальной принадлежности, развитие своей культуры. Для фактического преодоления «дискриминации в результате отсутствия дифференциации» недостает утверждения права каждого народа на самобытность.

Однако следует понимать, что утверждение в качестве «величайших ценностей», дружбы народов, самобытного развития каждого народа, самоидентификации и самоутверждения граждан-россиян, представителей отдельных национальностей и всего российского народа, единства многонационального народа России, стабильности и целостности - это проблема не только и даже не столько правовая, сколько идеологическая, духовная, политическая, ибо предполагает особый дух, атмосферу (уважение, доверие, взаимопонимание, дружбу, толерантность и т.п.), пронизывающую все слои общества, все его сферы и страты, всю его жизнедеятельность, отражающуюся в каждодневных делах и поступках, мыслях и намерениях.

Поэтому многие считают проблему защиты самобытности не столько правовой, сколько идеологической, если можно так сказать, общекультурной: право позволяет национальным общностям лишь быть замеченными, что не означает быть признанными равными. Подтверждение этой нашей мысли находим у Н. Стивенсона. Он пишет, что предоставляемые права «хотя и открывают необходимый для выживания доступ в общественное пространство, делают «видимыми» в общественной сфере определенные традиции, символы и т.п., еще недостаточны для их признания. Во всяком случае, если под признанием понимать нечто иное, чем простую «терпимость». Чтобы культура «обрела собственное гражданство» нужна «институционализация мультикультурных практик», нужен такой уровень культуры, чтобы каждый человек «относился с вниманием к аргументам других..., старался увидеть себя глазами другого, осмыслить свою деятельность в его понятиях и признать, что другой имеет право судить о твоем поведении» ${ }^{13}$.

\footnotetext{
${ }^{12}$ Конституции зарубежных стран (официальные тексты). - Доступно <http:www.uznal.org/constitution.php>.

${ }^{13}$ Стивенсон Н. Глобализация, национальные культуры и культурное гражданство // Глобализация: Контуры XXI века: Реф. сб. / РАН. ИНИОН. Центр научно-информ. исслед. глобальных и региональных пробл. Отд. Восточной Европы. - М., 2002. - Ч.ІІІ. - C. $11,13,14$.
} 


\section{Библиография:}

1. Брюшинкин В.Н. Идентичность в контексте глобализации: Европа, Россия, США: сборник научных статей. - Калинин, 2003. - 240 с.

2. В поисках путей модернизации: совместимы ли европейскость и самобытность («круглый стол») // Мировая экономика и международные отношения. - 2004. - № 10.- с. 113-122.

3. Глобализация и поиски национальной идентичности в странах Востока: сборник научных статей. - М., 1999. - $217 \mathrm{c}$.

4. Глобализация и развитие законодательства (очерки). - M., 2004. - 464 c.

5. Государство, этносы, сепаратизм и проблемы прав человека. Круглый стол: проблемы, дискуссии, предложения. - М.,2000.- 176 с.

6. Щербакова Н.В., Лукьянова Е.Г., Скурко Е.В. Правовая система России в условиях глобализации и региональной интеграции (Обзор материалов «круглого стола») // Государство и право. - 2004. - № 11. - С. 102-109.

7. Щербакова Н.В., Лукьянова Е.Г., Скурко Е.В. Правовая система России в условиях глобализации и региональной интеграции (Обзор материалов «круглого стола») (окончание) // Государство и право. - 2004. - № 12. - C. 86-92.

8. Габоев А.Б. Зашита прав и свобод человека - важнейший составной элемент при осуществлении государственной национальной политики // Государство и право. - 2005. - № 1. - С. 28-33.

9. Мартышин О.В. Национальная политическая и правовая культура в контексте глобализации // Государство и право. - 2005. - № 4. - С. 9-17.

10. Пантин В.И., Лапкин В.В. Трансформация национально-цивилизационной идентичности современного российского общества: проблемы и перспективы // Общественные науки и современность. - 2004. № $1 .-$ С. 52-56.

11. Поленина С.В. Мультикультурализм и права человека в условиях глобализации // Государство и право. 2005. - № 5. - С. 66-77.

12. Права и свободы народов в современной истории международного права (сборник документов). Казань, 1995. - 231 с.
13. Права народов. Международно-правовой толковый словарь. /Сост. и ред. Р. А. Тузмухамедов. - Уфа, 1996. - 135 с.

14. Сборник правовых актов Совета Европы о сохранении культурного наследия. Екатеринбург, 2001. - 620 с.

15. Сингер Б. Дж. Демократическое решение проблемы этнического многообразия // Вопросы философии. 1994. - № 6. - С. 91-102.

16. Словарь по правам человека. - Доступно $<$ http:www.hro.org/editions/glossary/10/colrights.htm>.

\section{References (transliteration): (transliteration):}

1. Bryushinkin V.N. Identichnost' v kontekste globalizacii: Evropa, Rossiya, SShA: sbornik nauchnyh statey. Kalinin, 2003. - 240 s.

2. Scherbakova N.V., Luk'yanova E.G., Skurko E.V. Pravovaya sistema Rossii v usloviyah globalizacii i regional'noy integracii (Obzor materialov «kruglogo stola») // Gosudarstvo i pravo. - 2004. - № 11. - S. 102-109.

3. Scherbakova N.V., Luk'yanova E.G., Skurko E.V. Pravovaya sistema Rossii v usloviyah globalizacii i regional'noy integracii (Obzor materialov «kruglogo stola») (okonchanie) // Gosudarstvo i pravo. - 2004. № 12. - S. 86-92.

4. Gaboev A.B. Zashita prav i svobod cheloveka - vazhneyshiy sostavnoy element pri osuschestvlenii gosudarstvennoy nacional'noy politiki // Gosudarstvo i pravo. - 2005. - № 1. - S. 28-33.

5. Martyshin O.V. Nacional'naya politicheskaya i pravovaya kul'tura v kontekste globalizacii // Gosudarstvo i pravo. - 2005. - № 4. - S. 9-17.

6. Pantin V.I., Lapkin V.V. Transformaciya nacional'nocivilizacionnoy identichnosti sovremennogo rossiyskogo obschestva: problemy i perspektivy // Obschestvennye nauki i sovremennost'. - 2004. - № 1. - S. 52-56.

7. Polenina S.V. Mul'tikul'turalizm i prava cheloveka v usloviyah globalizacii // Gosudarstvo i pravo. 2005. - № 5. - S. 66-77.

8. Prava narodov. Mezhdunarodno-pravovoy tolkovyy slovar'. /Sost. i red. R. A. Tuzmuhamedov. - Ufa, 1996. $-135 \mathrm{~s}$.

9. Singer B. Dzh. Demokraticheskoe reshenie problemy etnicheskogo mnogoobraziya // Voprosy filosofii. - 1994. - № 6. - S. 91-102. 